\title{
LA LIMITACIÓN DEL NÚMERO DE MANDATOS DEL PRESIDENTE DEL GOBIERNO
}

\author{
CRISTINA PAUNER CHULVI
}


SUMARIO

I. INTRODUCCIÓN. II. LA PROPUESTA DE LIMITAR EL NÚMERO DE MANDATOS DEL PRESIDENTE DEL GOBIERNO Y LAS FÓRMULAS ACTUALES DE LIMITACIÓN DEL NÚMERO DE MANDATOS DE LOS PRESIDENTES DE LAS COMUNIDADES AUTÓNOMAS. III. LA NECESIDAD DE ABORDAR UNA REFORMA CONSTITUCIONAL PARA INCLUIR EL LÍMITE DE MANDATOS DEL PRESIDENTE DEL GOBIERNO. 1. La limitación de mandatos presidenciales es ajena al sistema de gobierno parlamentario. 2. La limitación del número de mandatos es una materia vetada a la Ley del Gobierno porque excede el contenido que le autoriza la Constitución. 3. La restricción del derecho de participación política ha de configurarse como una limitación justificada, específica y proporcional para ser viable. 4. La restricción del número de mandatos afecta a las relaciones interinstitucionales y supone una triple limitación que condiciona a los sujetos intervinientes en el procedimiento ordinario de nombramiento tal y como lo configura la Norma fundamental. IV. CONCLUSIONES 


\title{
LA LIMITACIÓN DEL NÚMERO DE MANDATOS DEL PRESIDENTE DEL GOBIERNO
}

\author{
CRISTINA PAUNER CHULVI ${ }^{1}$ \\ Profesora Titular de Derecho Constitucional \\ Universitat Jaume I
}

\section{INTRODUCCIÓN}

En España, en los últimos tiempos, se ha hablado y discutido con frecuencia sobre la posibilidad de limitar el número de mandatos de los Presidentes del Gobierno ${ }^{2}$. La propuesta más reciente ha sido formalizada por el grupo parlamentario Ciudadanos el pasado 4 de septiembre de 2017 con la presentación en el Congreso de los Diputados de una Proposición de Ley de modificación de la Ley 50/1997, de 27 de noviembre, del Gobierno $^{3}$ en la que se determina un límite temporal que impide que una persona

${ }^{1}$ Profesora Titular de Derecho Constitucional. Departamento de Derecho Público. Edificio JC2. Facultad de Ciencias Jurídicas y Económicas. Universitat Jaume I. Avda. de Vicent Sos Baynat, s/n. E-12071 Castelló de la Plana. España.Email: pauner@uji.es

2 Así, la medida ya se contempló en agosto de 2016 en el pacto de gobierno suscrito entre el Partido Popular y Ciudadanos para facilitar la investidura de Rajoy ( «150 Compromisos para mejorar España», disponible en http://www.rtve.es/contenidos/documentos/documento_pp-cs.pdf). También el PSOE incluyó la propuesta de establecer un límite de dos mandatos consecutivos para ejercer la presidencia del Gobierno en su programa electoral para las elecciones generales de 2016 (PSOE, Programa Electoral. Elecciones generales 2016, pág. 77. Disponible en https://www.psoe.es/mediacontent/2016/05/PSOE-Programa-Electoral-2016.pdf). El establecimiento de un plazo máximo de ocho años consecutivos para ejercer el cargo de Presidente del Gobierno fue también una medida de reforma constitucional incorporada al Acuerdo de Gobierno que suscribieron el PSOE y Ciudadanos en febrero de 2016 (PSOE-Ciudadanos, Acuerdo para un Gobierno Reformista y de Progreso, 24 de febrero de 2016, pág. 65. Disponible en https://www.ciudadanos-cs.org/var/public/sections/page-home/ acuerdo-gobierno-reformista-y-de-progreso-2016.pdf?_ $\mathrm{v}=204 \_0$ ). A nivel doctrinal, recomendamos el excelente y completo análisis sobre la limitación de mandatos de cargos públicos de elección popular de Carlos Flores Juberías y José García-Contell MuÑoz, «La introducción en España de la limitación de mandatos: una aproximación crítica», Revista de Derecho Político, núm. 100, 2017, págs. 575-613.

3 BOCG. Congreso de los Diputados Núm. B-155-1 de 15/09/2017. 
pueda ostentar, la Presidencia del Gobierno durante más de ocho años seguidos, salvo que desde ese doble mandato hayan transcurrido otros cuatro.

El catalizador de esta propuesta $-\mathrm{y}$ de otras anteriores, bien frustradas o bien existentes en el nivel autonómico- es el creciente descontento social frente a la clase gobernante y los innumerables casos de corrupción que les envuelven. Así, los principales motivos que se esgrimen para incorporar esta novedad son los de erradicar la corrupción política, favorecer la regeneración institucional y dinamizar el conjunto del Estado democrático ya que el requisito contribuirá a garantizar la alternancia en el poder al impedir la perpetuación de una persona en un cargo que ostenta una relevante posición institucional.

Pero la iniciativa del grupo parlamentario Ciudadanos ha encontrado partidarios y detractores en las filas parlamentarias y ha desencadenado un debate jurídico muy intenso sobre la norma jurídica que debe contener la prohibición. De modo que frente a quienes defienden la legitimidad de la opción legal, existen sectores políticos y doctrinales que abogan por la necesidad de acometer una reforma constitucional sobre la base de las dificultades de encaje de tal medida en el sistema parlamentario español y la incidencia que tiene en el procedimiento ordinario de nombramiento del Presidente del Gobierno en los términos que establece el artículo 99 de la Constitución.

Desde el punta de vista del derecho comparado, la limitación de la permanencia en cargos públicos cuenta con gran tradición en los regímenes presidencialistas donde se restringe el número de mandatos en la Jefatura del Estado ${ }^{4}$ pero es inédita en democracias parlamentarias. Con todo, la tendencia a introducir límites a la reelección ya no es ajena al contexto europeo donde se ha debatido recientemente en torno a la limitación de los mandatos de los titulares de funciones públicas lo que incluye no solo a cargos del Ejecutivo sino también a parlamentarios 5 .

${ }^{4}$ En Estados Unidos la propuesta de limitar los mandatos representativos se extendió en los pasados noventa a partir de iniciativas legislativas populares y actualmente están establecidos en quince estados. De aquella época son fruto algunas publicaciones como Gerald BENJAMIN y Michael J. MALBON, Limiting Legislative Terms, CQ Press, Washington, D. C., 1992; John Charles ARMOR, Why Term Limits? Because They HaveIt Coming!, Jameson Books, Ottawa, 1994 llegando a formar parte del programa republicano presentado en la campaña electoral de 1994 por Newt GingriCH y Dick Armey en Contract with America, Washington, D. C., 1994. Más recientemente puede verse Karl T. KurTz, Bruce CaIN and Richard G. NiemI, Institutional Change in American Politics: The Case of Term Limits, University of Michigan Press, Michigan, 2007.

5 El Informe de la Comisión de Venecia sobre la democracia, la limitación de mandatos y la incompatibilidad de las funciones públicas afirma que «La démocratie moderne peut uniquement fonctionner si elle se dote de certaines limites qu'elle juge légitimes et raisonnables. Naturellement, la limitation du mandat des titulaires de fonctions politiques et de leur droit d'être (ré)élus, ainsi que les incompatibilités de nature politique et économique et l'interdiction de se présenter aux élections sont des institutions clés qui limitent la démocratie, tout en la rendant possible» (Comisión Europea para la democracia a través del derecho del Consejo de Europa, Rapport sur la démocratie, la limitation des mandats et l'incompatibilité de fonctions politiques, 17 de diciembre de 2012, pág. 5). 
En nuestro derecho positivo, la limitación de la renovación de mandatos es muy frecuente aplicada a miembros de determinadas instituciones públicas de control como el Tribunal Constitucional, Tribunal de Cuentas, Defensor del Pueblo o las conocidas como Administraciones independientes con la finalidad de garantizar que los integrantes de estos organismos ejerzan sus funciones con independencia e imparcialidad. Por el contrario, no existe en España ninguna legislación que regule la limitación de mandatos de cargos políticos a nivel nacional aunque estuvo redactado el artículo preciso que iba a plasmarla en la Constitución de 1978 con el siguiente tenor: «Una misma persona no puede ser Presidente del Gobierno o de una Comunidad Autónoma más de ocho años».

En cualquier caso, la propuesta de limitar el número de mandatos del Presidente del Gobierno no es radicalmente novedosa en el panorama político español puesto que, como veremos con más detalle, la no reelección presidencial rige ya a nivel autonómico en Castilla-La Mancha, Extremadura y Murcia, está regulada en las autonomías de Cataluña y Castilla y León y durante 2017 ha sido reivindicada en Madrid por Ciudadanos y en Andalucía por el Partido Popular.

En las líneas que siguen presentamos un detallado análisis de la forma y el contenido de la propuesta de no reelección presidencial y su afectación al procedimiento ordinario de formación del Gobierno. Como elemento comparativo, se estudiarán las fórmulas restrictivas del número de mandatos que las Comunidades Autónomas han incorporado en sus ordenamientos. Seguidamente, se presentarán los argumentos sobre los que se trata de fundamentar la legitimidad de la opción legal para incorporar la limitación de mandatos para, a continuación, rebatir estas razones y apostar por la necesidad de operar una reforma constitucional que dé cobertura a la novedosa condición legal.

\section{LA PROPUESTA DE LIMITAR EL NÚMERO DE MANDATOS DEL PRESIDENTE DEL GOBIERNO Y LAS FÓRMULAS ACTUALES DE LIMITACIÓN DEL NÚMERO DE MANDATOS DE LOS PRESIDENTES DE COMUNIDADES AUTÓNOMAS}

La propuesta de limitar el número de mandatos presidenciales se produce en un momento en el que el diseño constitucional de la investidura del Presidente del Gobierno ha sido objeto de especial atención a consecuencia del fragmentado panorama político surgido tras las dos convocatorias electorales de 2015 y $2016^{6}$. El

${ }^{6}$ Un riguroso análisis de las cuestiones planteadas durante la XI y XII Legislaturas en torno a la regulación constitucional de la investidura parlamentaria del Presidente del Ejecutivo en Germán M. Teruel Lozano, «La regulación constitucional de la investidura del Presidente del Gobierno ante un nuevo escenario político», Comunicación presentada al XII Congreso de la Asociación de Constitucionalistas de España, 30 y 31 de marzo de 2017, disponible en https://congresoace.files.wordpress. com/2017/03/mesa3comunicaciongteruel.pdf; Rosario GARCía MAHAMUT, «La reforma de la LOREG 
nuevo escenario ha sometido a tensiones al procedimiento previsto en el artículo 99 de la Constitución, un proceso flexible y no pormenorizado que se ha revelado eficaz hasta el momento y ha recibido una valoración positiva.

El Gobierno se configura como un órgano central en el sistema constitucional español tanto por las concretas tareas que tiene atribuidas como la importante función de estímulo, orientación e impulso de la acción de otros órganos que le corresponde desarrollar ${ }^{7}$. A esta centralidad del Ejecutivo debe sumarse la indiscutible preeminencia del Presidente del Gobierno derivada del estatuto jurídico político que la Constitución le confiere y acrecentada por la práctica política que ha introducido elementos de carácter presidencialista en nuestro sistema de gobierno ${ }^{8}$.

También por su origen y designación, el Presidente del Gobierno se erige en una figura sobresaliente frente al resto de miembros del Gobierno9. Así, el procedimiento parlamentario de formación de Gobierno se concentra en la designación del Presidente quien, una vez investido de la confianza parlamentaria, elegirá al resto de miembros del Ejecutivo. Concretamente, el artículo 99.1 de la Constitu-

para el supuesto de convocatoria automática de elecciones en virtud del artículo 99.5 CE ¿una oportuna adaptación técnica o una conculcación del derecho de sufragio?», Revista de Derecho Político, núm. 100, 2017, págs. 541-573; Juan J. SOlOzÁBAL ECHAvARRíA, «La problemática constitucional de la formación del Gobierno y la intervención del monarca en nuestro régimen parlamentario» y Miguel Revenga SÁnchez, «La funcionalidad del artículo 99 de la Constitución ante el caso de un resultado electoral fragmentado: ¿mejorar su aplicación o proponer su reforma?», ambos en Revista Española de Derecho Constitucional, núm. 109, 2017, págs. 35-61 y 97-120, respectivamente. Sobre las alternativas al sistema español de nombramiento del Presidente del Gobierno derivadas de la experiencia constitucional comparada, véase Ignacio TORRES MURO, «La reforma del procedimiento ordinario de nombramiento del Presidente del Gobierno», Teoría y Realidad Constitucional, núm. 30, 2012, págs. 315-334.

7 Luis López Guerra, «El Gobierno», en AAVV, Derecho constitucional, vol. II, Tirant lo Blanch, Valencia, 2016, 10. ${ }^{a}$ ed., págs. 134 y 135. La bibliografía sobre el Gobierno es inabarcable por lo que nos limitaremos a mencionar los estudios de Ignacio DE OTTO Y PARDO, «La posición constitucional del Gobierno», Documentación Administrativa, núm. 188, 1980, págs. 139-182; Joan Lluís Pérez Francesch, El Gobierno, Tecnos, 1993; Miguel Revenga Sánchez, La formación del Gobierno en la Constitución Española de 1978, CEC, Madrid, 1988; Patricia Rodríguez Patrón, «El Gobierno como órgano constitucional», en VVAA, El Gobierno. Problemas constitucionales, CEPC, Madrid, 2005 y Javier García Fernández, Estudios sobre el Gobierno, INAP, Madrid, 2007.

${ }^{8}$ Sobre la posición sobresaliente del Presidente del Gobierno en la estructura y funciones del ejecutivo pueden verse, entre muchos otros, las reflexiones contenidas en la «Encuesta sobre el Gobierno», Teoría y Realidad Constitucional, núm. 14, 2004, págs. 11-84; Ignacio FernándeZ SARASOla, «Algunas reflexiones en torno a la primacía del Presidente en el gabinete ministerial», Teoría y Realidad Constitucional, núm. 16, 2005, págs. 279-293; Óscar I. MATeOS y DE CABO, El Presidente del Gobierno de España, La Ley-Universidad Rey Juan Carlos, Madrid, 2006; Antonio Bar Cendón, El Presidente del Gobierno en España. Encuadre constitucional y práctica política, Civitas, Madrid, 1983.

9 Por todos, Antonio BAR CENDÓN, «Nombramiento del Presidente del Gobierno», en Comentarios a la Constitución Española de 1978, Edersa, Madrid, 1996, págs. 245-306; Miguel RevenGa SánCHez, «Veinticinco años de formación de Gobierno», Revista de Derecho Político, núms. 58-59, 2003-2004, págs. 503-522 y Joan VINTRó CASTELls, La investidura parlamentaria del Gobierno: perspectiva comparada y Constitución española, Congreso de los Diputados, Madrid, 2006. 
ción contempla la fórmula ordinaria y establece que «Después de cada renovación del Congreso de los Diputados, y en los demás supuestos constitucionales en que así proceda, el Rey, previa consulta con los representantes designados por los grupos politicos con representación parlamentaria, y a través del Presidente del Congreso, propondrá un candidato a la Presidencia del Gobierno».

La configuración normativa del Presidente del Gobierno se completa con la mencionada Ley 50/1997 del Gobierno. La Exposición de Motivos de esta Ley confirma la preeminencia del Presidente que se destaca como rasgo consustancial a todos los sistemas de gobierno pues «el Derecho Comparado es prácticamente unánime en consagrar la existencia de un evidente desequilibrio institucionalizado entre la posición del Presidente, de supremacía, y la de los demás miembros del Gobierno». Por otra parte y a pesar de la inexistencia de condiciones de acceso al cargo de Presidente en la Constitución, la Ley del Gobierno sí ha introducido unos requisitos para ser miembro del Gobierno lo que es extensible al Presidente. Su artículo 11 establece que «Para ser miembro del Gobierno se requiere ser español, mayor de edad, disfrutar de los derechos de sufragio activo y pasivo, así como no estar inhabilitado para ejercer empleo o cargo público por sentencia judicial firme y reunir el resto de requisitos de idoneidad previstos en la Ley 3/2015, de 30 de marzo, reguladora del ejercicio del alto cargo de la Administración General del Estado».

La propuesta de limitación del número de mandatos del Presidente del Gobierno se articularía a través de esta Ley del Gobierno, sin reforma constitucional y añadiendo un segundo apartado al mencionado artículo que establezca que «2. Para ser nombrado Presidente del Gobierno se requiere, además de los requisitos del apartado anterior, no haber ostentado, de manera continua, el cargo durante ocho años, salvo que, desde el agotamiento del plazo, hubiese transcurrido otro de cuatro años. El agotamiento del plazo durante el desempeño del cargo, no será causa de cese». Esta regla impediría la reelección del candidato para un tercer mandato siempre que los mandatos anteriores sumasen ocho años y no hubieran transcurrido otros cuatro desde el último, situación que, en cuarenta y un años de democracia, se ha producido en una única ocasión en nuestro país. Así, la historia constitucional española desde 1978 nos muestra que solo en una ocasión se ha superado ese límite de ocho años con Felipe González quien ocupó la Presidencia del Gobierno durante cuatro legislaturas entre 1982 y 1996 (II a V Legislaturas) gobernando a lo largo de trece años y medio.

La norma fija, por tanto, una prohibición parcial porque solo afecta a ese cargo público electivo y relativa en el sentido de que no es un requisito que imposibilitaría, de manera indefinida, a una persona el desempeño futuro del cargo puesto que una vez superado un nuevo plazo de cuatro años, podría volver a ser propuesto para la Presidencia del Gobierno ${ }^{10}$. Además, el nuevo apartado añade, en un inciso final, que

10 Antonio IBÁÑez Macías, «La limitación de mandatos parlamentarios: una técnica constitucional para la renovación permanente de las élites políticas», Revista de Derecho UNED, núm. 17, 2015, págs. 342-343. 
el agotamiento del plazo durante el desempeño del cargo no puede condicionar la permanencia en el mismo y no será causa de cese.

Finalmente, la restricción del derecho a la reelección se aplicaría, en su caso, a los electos después de la entrada en vigor de la modificación pero no a quienes accedieron a dicho cargo sin que la limitación de mandatos existiera para evitar efectos retroactivos de normas limitadoras de derechos, prohibidos por el artículo 9.3 de la Constitución.

La fórmula propuesta en el ámbito nacional guarda una semejanza considerable con las disposiciones que, en los últimos años, se han ido introduciendo en los ordenamientos autonómicos para limitar el número de mandatos de los Presidentes de las Comunidades Autónomas. También en estos casos encontramos que el tipo de norma que contiene la restricción es dispar regulándose bien en el Estatuto de Autonomía bien en normas de rango legal muy heterogéneas que van desde la respectiva ley del Gobierno a la ley electoral autonómica pasando por la ley del estatuto del Consejo de Gobierno.-

Hasta el momento, dos Comunidades Autónomas — Castilla-La Mancha y Cataluña- la han recogido en su respectivo Estatuto de Autonomía. Castilla-La Mancha fue la primera autonomía en legislar sobre la limitación de mandatos presidenciales incluyendo esta condición de acceso en el artículo 13.2 del Estatuto de Autonomía ${ }^{11}$, previsión que desarrolló en su Ley de Gobierno en 1997, actualmente derogada por la Ley 11/2003 que mantiene la misma redacción. La limitación se extiende a quien ocupe el cargo durante al menos ocho años excepto si ya han transcurrido otros cuatro $a_{n ̃ o s}{ }^{12}$. Esta fórmula permite volver a presentarse a unas terceras elecciones tanto a quien no ha agotado los cuatro años en uno de los dos mandatos como a aquel Presidente que haya dejado de serlo transcurridos cuatro años desde la terminación de su último mandato. En Cataluña, el artículo 67.2 de la Ley Orgánica 6/2006, de 19 de julio, de Reforma del Estatuto de Autonomía de Cataluña establece que «El Presidente o Presidenta de la Generalitat es elegido por el Parlamento de entre sus miembros. Puede regularse por ley la limitación de mandatos». La habilitación estatutaria aún no ha tenido desarrollo legal.

Más recientemente, otras Comunidades Autónomas han implantado la mencionada limitación en virtud de una ley autonómica sin disposición estatutaria expresa. Es el caso de Extremadura que ha legislado sobre la imposibilidad de reelección del

11 Artículo 13.2 de la Ley Orgánica 9/1982, de 10 de agosto, de Estatuto de Autonomía de Castilla-La Mancha modificado por Ley Orgánica 3/1997, de 3 de julio: «El Consejo de Gobierno se compone del Presidente, de los Vicepresidentes, en su caso y de los Consejeros. Las Cortes de Castilla-La Mancha, por mayoría de tres quintos de los miembros del Pleno de la Cámara, aprobarán una Ley del Gobierno y del Consejo Consultivo en la que se incluirá la limitación de los mandatos del Presidente».

12 Artículo 4.2 de la Ley 11/2003, de 25 de septiembre, de Gobierno y Consejo Consultivo de Castilla-La Mancha: «No podrá ser elegido Presidente de la Junta de Comunidades quien ya hubiese ostentado este cargo durante al menos ocho años, salvo que hayan pasado cuatro años desde la terminación de su mandato». 
Presidente del Ejecutivo autonómico tras dos mandatos consecutivos permitiéndola transcurridos cuatro años desde el último mandato y si el candidato no ha agotado los ocho años de mandato previos. Esta Comunidad Autónoma se ha decantado por incluir este plazo en el artículo 8.3 de la Ley del Estatuto de los Cargos Públicos del Gobierno y la Administración de Extremadura de 2014³. La Exposición de Motivos de la Ley $1 / 2014$ justifica la habilitación estatutaria para elaborar y aprobar la norma en el artículo 9.1.1 del Estatuto que atribuye a la Comunidad Autónoma de Extremadura, con carácter pleno, sobre la «Creación, organización, régimen jurídico y funcionamiento de sus instituciones, así como la organización de su propia Administración y la de los entes instrumentales que de ella dependan» y en el artículo 24.2 del mismo texto que remite al legislador la regulación del estatuto del Presidente de la Junta de Extremadura.

También en 2014 se modificó la Ley 6/2004, de 28 de diciembre, del Estatuto del Presidente y del Consejo de Gobierno de la Región de Murcia cuyo artículo 7 , sobre elección del Presidente, establece en su apartado segundo que «No podrá ser elegido Presidente de la Comunidad Autónoma quien ya bubiese ostentado este cargo durante dos mandatos» sin lugar a más alternativas. El Estatuto de Autonomía para la Región de Murcia tampoco contempla la supresión del derecho a la reelección de ningún cargo público.

Finalmente, por lo que se refiere a Castilla y León, la restricción de mandatos se contempla en la Ley del Estatuto de los Altos Cargos de 2016 que limita los mandatos del Presidente ${ }^{14}$ y los consejeros ${ }^{15}$. La norma determina que quienes hayan ocupado durante ocho años la presidencia de la Junta de Castilla y León no podrán ser propuestos para su reelección en la misma institución, mientras que en el caso de los consejeros, no podrán ser nombrados para dirigir una consejería que ya hayan encabezado durante ocho años.

El acuerdo político alcanzado en las sedes parlamentarias autonómicas permitió que se adoptaran estas limitaciones en el articulado de las respectivas leyes aunque, en su mayoría, no estaban respaldadas por los dictámenes no vinculantes evacuados

13 Artículo 8.3 de la Ley 1/2014, de 18 de febrero, de regulación del estatuto de los cargos públicos del Gobierno y la Administración de la Comunidad Autónoma de Extremadura: «No podrá ser elegido presidente de la Junta de Extremadura quien ya hubiese ostentado este cargo durante dos mandatos sucesivos, salvo que hayan pasado cuatro años desde la terminación de su mandato y sin que en ningún caso pueda ser elegido quien hubiera ostentado este cargo durante al menos ocho años».

14 Disposición adicional primera de la Ley 3/2016, de 30 de noviembre, del Estatuto de los Altos Cargos de la Administración de la Comunidad de Castilla y León: «Las personas que hayan ostentado durante ocho años la presidencia de la Junta de Castilla y León o la presidencia o titularidad de alguna de las instituciones propias de la Comunidad de Castilla y León no podrán ser propuestas para su reelección en la misma Institución».

15 Artículo 2.2 de la Ley 3/2016: «En el caso de los miembros del gobierno, no podrán ser nombrados como titulares de una consejería quienes ya lo hubieran sido de ese mismo departamento durante ocho años». 
por los órganos consultivos autonómicos ${ }^{16}$. En síntesis, las objeciones jurídicas más relevantes se basaban, en primer lugar, en las dificultades de encaje de una fórmula típica de un modelo presidencialista en un modelo de parlamentarismo racionalizado $\mathrm{y}$, en segundo término, en la necesidad de contar con una habilitación previa en un tipo de leyes que, por su materia y por el procedimiento formal que exigen para su aprobación, adquieren el rango de orgánicas ya que la prohibición de ser reelegido como Presidente es una restricción en el ejercicio del derecho de participación política consagrado en el artículo 23 de la Constitución que «de existir, tendría que estar recogida de forma clara e inequívoca en una norma de rango adecuado (artículo 70.1 de la Constitución), como la Ley Orgánica 5/1985, de 19 de junio, de Régimen Electoral General (LOREG) o en el propio Estatuto de Autonomía» ${ }^{17}$. Como modelo se sugiere que cualquier modificación en la limitación de mandatos de la presidencia del Gobierno, debería estar contemplada en el Estatuto de Autonomía, como ocurre en Cataluña y Castilla-La Mancha.

\section{LA NECESIDAD DE ABORDAR UNA REFORMA CONSTITUCIONAL PARA INCLUIR EL LÍMITE DEL NÚMERO DE MANDATOS DEL PRESIDENTE DEL GOBIERNO}

Las ventajas que cabe esperar de la limitación del número de mandatos de los titulares de cargos representativos ya han sido señaladas y el hecho de que esta convicción se extienda paulatinamente en el contexto político actual confirma la convic-

16 En Asturias, la aprobación de la limitación de mandatos estaba prevista dentro de la reforma de la Ley del Presidente que decayó por falta de apoyo parlamentario. En esta Comunidad, el Dictamen 45/2014, de 13 de marzo de 2014, de Consejo Consultivo del Principado de Asturias avaló la viabilidad jurídica de la limitación legal del periodo de duración del mandato del Presidente sin necesidad de previa habilitación estatutaria. Sus conclusiones cabe resumirlas como sigue: 1. Dicha limitación no supone la vulneración del derecho fundamental del artículo 23.2 de la Constitución por el carácter de elección de segundo grado del Presidente de la Comunidad Autónoma; 2. Es posible introducir la limitación por reforma estatutaria, pero no de forma obligatoria; y 3. La limitación de mandatos afecta de lleno al estatuto del Presidente por lo que debe introducirse a través de una modificación de la Ley 6/1984, de 5 de julio, del Presidente y del Consejo de Gobierno del Principado de Asturias y no hacerlo en una disposición adicional del anteproyecto autonómico de buen gobierno y régimen de incompatibilidades.

17 Dictamen, de 19 de mayo de 2016, del Consejo Consultivo de Castilla y León sobre el anteproyecto de Ley por el que se regula el Estatuto de los Altos Cargos de la Administración de la Comunidad de Castilla y León. Similares argumentos se recogen en el Dictamen 534/2013, de 31 de octubre, del Consejo Consultivo de Extremadura sobre el Anteproyecto de ley por el que se regula el Estatuto de los cargos públicos del Gobierno y la Administración de la Comunidad Autónoma de Extremadura y en el Dictamen 358/2017, del Consejo Consultivo de Andalucía que descartó la introducción de este límite en la Proposición de Ley del Grupo Parlamentario popular andaluz relativa a la modificación de la Ley 6/2002, de 24 de octubre, del Gobierno de la Comunidad Autónoma de Andalucía.. 
ción en las bondades de la propuesta ${ }^{18}$. Desaparecida la alusión a la corrupción de la Exposición de Motivos de la proposición legislativa que estamos analizando, la renovación permanente de las elites políticas y la conveniencia de la regeneración institucional son las más destacadas en la propuesta de Ciudadanos.

Queda fuera del objeto de estas líneas valorar la oportunidad o conveniencia de adoptar esta propuesta para lo que sería necesario un análisis en profundidad sobre su impacto en las agrupaciones partidistas o un contraste riguroso de la eficacia de la medida en los sistemas que ya han implantado la restricción ${ }^{19}$. En cambio, las consideraciones que siguen tratan de reflexionar sobre el tipo de norma que debe contener la limitación del número de mandatos.

A juicio de los promotores, la introducción de este nuevo requisito en el texto de la Ley del Gobierno se entendería habilitada por la reserva legal que realiza el artículo 98.4 de la Constitución que dispone que «La ley regulará el estatuto e incompatibilidades de los miembros del Gobierno». Partiendo de esta habilitación, se trata, afirman, de una condición equiparable a las que ya se enumeran en el artículo 11 de la Ley del Gobierno. Desde el punto de vista subjetivo del candidato, esa limitación no conculcaría el derecho fundamental a acceder a funciones y cargos públicos porque el artículo 23.2 de la Constitución contiene una remisión a los requisitos que establezcan las Leyes y no existe un derecho fundamental a ser propuesto como Presidente del Ejecutivo puesto que la propuesta recae sobre el Rey y debe contar con el aval del Congreso. Debe entenderse que la limitación de mandatos es una restricción del derecho de sufragio pasivo pero que en ningún caso entraña una negación del mismo. Sólo una limitación de mandatos total (para cualquier cargo público electivo) y absoluta (de por vida), supondría en lo sucesivo una negación del derecho de sufragio pasivo para la persona que incurriera en la misma. Desde el punto de vista de los electores, sostienen que el cargo de Presidente del Gobierno no es un cargo público de representación directa sino que se trata de una elección de segundo grado por lo que no afecta al derecho de los ciudadanos a participar en los asuntos públicos por medio de sus representantes elegidos por sufragio universal (artículo 23.1 de la Constitución).

Frente a esta postura, entendemos que la introducción de esta cláusula exige abordar una reforma de la Constitución en atención a varios argumentos.

${ }^{18}$ Carlos Flores y Jorge García-Contell desarman concienzudamente las supuestas bondades de esta propuesta como antídoto frente a la corrupción ( «La introducción en España de la limitación de mandatos»..., págs. 591 y ss).

19 Efectos como las dificultades de encontrar relevos en partidos o agrupaciones electorales de tamaño reducido, o la consecución parcial de objeticos — alterando la carrera política de las elites pero no cambiándola - son objeciones que se esgrimen frente a la prohibición de reelección. A todas estas cuestiones da respuesta el artículo citado de Antonio IBÁÑEZ Macías, «La limitación de mandatos parlamentarios: una técnica constitucional para la renovación permanente de las élites políticas»..., págs. 341-389. 


\section{La limitación de mandatos presidenciales es ajena al sistema de gobierno parlamentario}

Como es bien sabido en el ámbito del derecho comparado, la limitación de mandatos de la Jefatura del Estado es una fórmula típica de sistemas de gobierno presidenciales o semipresidenciales organizados sobre una separación rígida de poderes donde el mandato del jefe del Ejecutivo es fijo e inalterable por la acción de las cámaras $^{20}$. Los primeros antecedentes de esta fórmula surgieron en el contexto de las Constituciones iberoamericanas debido a la negativa influencia que ejercía el ejemplo de la Monarquía española ${ }^{21}$. Las Constituciones de Argentina de 1819, Chile de 1822 o México de 1814 limitaron la reelección de sus presidencias bajo diversas fórmulas y actualmente es la regla mayoritaria en el contexto constitucional iberoamericano ${ }^{22}$. Con todo, el paradigma de prohibición de reelección presidencial es el de la Constitución de los Estados Unidos de América cuya Enmienda XXII ${ }^{23}$ transformó la costumbre constitucional de la no reelección para un tercer mandato en prohibición de elegibilidad. El objetivo de la restricción a la reelección presidencial es eliminar los riesgos derivados de la reiteración de mandatos a causa de la limitada responsabilidad política del titular del Ejecutivo ante la representación de la soberanía ya sea porque su nombramiento derive de la elección directa de los ciudadanos o bien porque, elegido por la Cámara, esta no pueda exigir tal responsabilidad.

Frente a esta lógica, en el modelo de parlamentarismo racionalizado que establece la Constitución española no parece congruente la limitación del número de man-

20 Sobre tipología de las formas políticas y el concepto de sistemas de gobierno, véase Antonio Torres del Moral, Estado de Derecho y democracia de partidos, Editorial Universitas-UNED, Madrid, 2015, 5. ed., págs. 277 a 289, especialmente, pág. 288.

21 Javier García FernándeZ, «La limitación del mandato del Presidente del Gobierno», Sistema Digital, 2 de enero de 2017, http://www.fundacionsistema.com/la-limitacion-del-mandato-del-presidente-del-gobierno/

${ }^{22}$ Las soluciones constitucionales al problema de la reelección en Latinoamérica son variadas. Sin ánimo exhaustivo, algunas Constituciones admiten la reelección inmediata una vez (Venezuela); la reelección consecutiva una sola vez (Argentina, Ecuador o Venezuela), la reelección no inmediata (Brasil, Uruguay y Perú) o prohíben la reelección (Chile y Paraguay). Sobre el tema, in extenso, C. Flores Juberías y Jorge García-Contell MuÑoz, «La introducción en España de la limitación de mandatos»..., págs. 584 a 591 y Eduardo Rozo ACUÑA, «Inelegibilidad e irrelegibilidad en el Derecho Público Latinoamericano", en Tratado de Derecho Electoral comparado de América Latina, IIDH/CAPEL, México, 1998, págs. 101-119.

${ }^{23}$ Enmienda XXII de la Constitución de Estados Unidos de América de 1787: «1. No se elegirá a la misma persona para el cargo de Presidente más de dos veces, ni más de una vez a la persona que haya desempeñado dicho cargo o que haya actuado como Presidente durante más de dos años de un período para el que se haya elegido como Presidente a otra persona. El presente artículo no se aplicará a la persona que ocupaba el puesto de Presidente cuando el mismo se propuso por el Congreso, ni impedirá que la persona que desempeñe dicho cargo o que actúe como Presidente durante el período en que el repetido artículo entre en vigor, desempeñe el puesto de Presidente o actúe como tal durante el resto del referido período». Esta enmienda fue aprobada por el Congreso el 21 de marzo de 1947 y ratificada por el número necesario de estados el 27 de febrero de 1951. 
datos del Presidente del Gobierno cuyo poder emana de un Parlamento que representa la soberanía nacional y que somete a control permanente al titular del Ejecutivo por lo que su duración en el cargo dependerá del mantenimiento de la confianza del legislativo.

No cabe desconocer que muchos autores han destacado los rasgos de «presidencialización» de nuestro sistema al tratarse de un sistema de parlamentarismo fuertemente condicionado por la preponderancia de la figura del Presidente ${ }^{24}$. Esta prevalencia del titular del Ejecutivo es fruto de la combinación de causas políticas como la personalización de las elecciones parlamentarias y causas jurídicas derivadas del sistema de gobierno diseñado por la Constitución que le atribuye un amplio margen de maniobra en un marco institucional de preeminencia. Sin embargo, estas realidades que favorecen la estabilidad de un gobierno de canciller no destruyen la lógica sobre la que descansa la forma parlamentaria de gobierno en la que el vínculo fiduciario ocupa una posición de centralidad dejando en manos de la coalición legislativa mayoritaria la determinación de quién ocupa el Gobierno y hasta cuándo. Se trata, pues, de un criterio jurídico irreductible que no puede desconocerse $\mathrm{e}^{25}$.

\section{La limitación del número de mandatos es una materia vetada a la Ley del Gobierno porque excede el contenido que le autoriza la Constitución}

La Constitución no ha previsto una reserva de ley sobre el Gobierno como sí ha hecho, por ejemplo, en su artículo 70 en relación con la Ley electoral para regular las inelegibilidades e incompatibilidades.

En relación con el Gobierno encontramos, en primer lugar, una reserva genérica en el artículo 97 de la Constitución que establece que «El Gobierno ejerce sus funciones de acuerdo con la Constitución o las leyes» y en el artículo 103 CE sobre la Administración y, en segundo lugar, dos reservas de ley específicas en el artículo 98.1 de la Constitución sobre la composición del Gobierno y el artículo 98.4 de la Constitución sobre el estatuto e incompatibilidades de los miembros del Gobierno. Estas reservas se han concretado en la Ley 50/1997 del Gobierno y la normativa sobre el estatuto de incompatibilidades de los miembros del Gobierno. Las consecuencias son que la Constitución no impide una Ley del Gobierno general pero no la ha previsto expresamente. El legislador debe, por tanto, desarrollar las reservas previstas en la Constitución con cautela y ceñirse estrictamente al contenido legal «reservado» por

${ }^{4}$ Por todos, véase Manuel García CANALES, «La huella presidencialista en el constitucionalismo español», Revista Española de Derecho Constitucional, núm. 44, 1995, págs. 99-127 y VVAA, «Encuesta sobre el Gobierno»..., págs. 14-19.

25 Philippe Lavaux, Les grandes démocraties contemporaines, PUF, Paris, 1998, pág. 167 (citado en Joan Vintró Castells, La investidura parlamentaria del Gobierno: perspectiva comparada y Constitución española, cit., pág. 13). 
la Norma fundamental, esto es, la composición del Gobierno y el estatuto de sus miembros que no es lo que hace stricto sensu la Ley del Gobierno que va mucho más allá con el establecimiento completo de su régimen.

Entendemos que la remisión que realiza el artículo 98.4 de la Constitución no da cobertura al establecimiento legal de condiciones materiales que inhabiliten para el acceso al cargo del candidato a la Presidencia del Gobierno por lo que no cabe declararla en la Ley del Gobierno puesto que, en primer lugar, se trata de una ley ordinaria — no orgánica - que no puede regular materias que afecten al desarrollo directo del derecho fundamental de participación política y, en segundo término, de haberse consignado en una norma de rango orgánico — como pudiera ser mediante la reforma de la Ley Orgánica de Régimen Electoral General que regula las causas de inelegibilidad e incompatibilidad en nuestro sistema electoral- la limitación del número de mandatos presidenciales exigiría una justificación proporcional al derecho de participación limitado. Cualquier restricción debe configurarse respetando el mandato de la norma constitucional y la esencia del derecho de sufragio pasivo (STC 28/1986, de 20 de febrero), condición que comentamos en detalle más abajo.

Así, la previsión constitucional de formación ordinaria del Gobierno no establece condición alguna ni remite a sede legal para su determinación de forma que una ampliación de requisitos para el acceso al cargo deberá contar con la habilitación previa en el Texto fundamental ${ }^{26}$.

\section{La restricción del derecho de participación politica ba de configurarse como una limitación justificada, específica y proporcional para ser viable}

Las reglas de la democracia representativa dicen que los mandatos dependen siempre de la voluntad de los votantes y, pese a la importancia que tiene la renovación en el gobierno para la teoría democrática, no es en sí misma un principio democrático equiparable a la regla de la elección popular de los gobernantes y a la periodicidad de los procesos electorales. En otras palabras, «en un régimen democrático, la reiteración en la determinación de mayorías por parte de la ciudadanía no es sino una parte más de las posibilidades del ejercicio de participación ciudadana, de tal forma que su restricción por medio de una Ley supondría una limitación de las posibilidades de desempeño democrático» ${ }^{27}$.

26 En el mismo sentido, Germán M. Teruel Lozano, «La regulación constitucional de la investidura del Presidente del Gobierno ante un nuevo escenario político»..., pág. 4, nota a pie 20 y Javier García Fernández, «La limitación del mandato del Presidente del Gobierno»...

27 Dictamen 4/2013, de 12 de junio, del Consejo Económico y Social de Extremadura sobre el Anteproyecto de ley por la que se regula el Estatuto de los cargos púbicos del Gobierno y de la Administración de la Comunidad Autónoma de la Comunidad Autónoma de Extremadura. 
La supresión del derecho del candidato a la reelección impide el convertirse, en quien concurra, en sujeto pasivo de la relación electoral privándole del derecho de sufragio pasivo mientras que este derecho queda inalterado para el resto de sujetos (STC 155/2014, de 25 de septiembre, fj 2). Esta medida debe construirse partiendo de dos premisas. La primera es que tratándose de una restricción a un derecho fundamental debe articularse como una limitación específica, en términos razonables y proporcionales del derecho al sufragio «por su consideración de principio básico de la organización del Estado y del carácter democrático del Estado como un elemento básico de todo el sistema constitucional» (STC 26/1990, de 19 de febrero, fj 6). De ahí que la limitación tenga una justificación compleja en una democracia como la que instaura la Constitución española que formula la soberanía popular como basamento nuclear e irreductible del ordenamiento jurídico (artículo 1.2). De lo anterior se deduce que partimos, en principio, de la libertad de todos los ciudadanos para alcanzar un estatus político activo y, por tanto, la posibilidad de solicitar de los electores su voto con el propósito de acceder a los cargos y funciones públicas. Por ello, es del Texto constitucional del que parte y legitima la existencia de algunas restricciones a este derecho fundamental.

En este sentido, es apropiado recordar que también en Estados Unidos las limitaciones de mandatos han sido declaradas inconstitucionales en algunos supuestos. En tres estados - Massachusetts (medida adoptada en 1994 y declarada inconstitucional en 1997), Washington (1992 y 1998 respectivamente) y Wyoming (1992 y 2004 respectivamente)_, en los que los límites de mandato fueron establecidos vía iniciativa legislativa popular, los tribunales supremos estatales declararon que las limitaciones de mandato constituían un requisito adicional para los cargos públicos y que, en consecuencia, solo podían ser establecidas por la Constitución y no por las leyes ${ }^{28}$.

Es indiscutible que el derecho de sufragio pasivo, como todos los derechos constitucionales, no es absoluto y el propio artículo 23.2 de la Constitución lo supedita a los requisitos que señalen las leyes de modo que el acceso a la Presidencia será factible tras reunir los requisitos legales. Además, «nadie, como se comprende, ostenta frente a sus conciudadanos un derecho fundamental para ser por ellos propuesto y presentado, a través de tales organizaciones o agrupaciones, como candidato en unas elecciones» (STC 78/1987, de 26 de mayo, fj 3). Sin embargo, también es necesario que el requisito de acceso no se plantee en la norma de manera irrestricta e incondicionada, es decir, sin que exista una fundamentación que quepa entender como «justificación objetiva y razonable, pues lo que este último precepto ordena es que no se produzcan acepciones o pretensiones ad personam en el acceso a las funciones públicas» (SSTC 8/1985, de 12 de febrero; 148/1986, de 25 de noviembre y 18/1987, de 16 de febrero).

${ }^{28}$ Pueden consultarse estas y posteriores decisiones judiciales sobre límites a la reelección en Estados Unidos en National Conference of State Legislatures (NCSL), http://www.ncsl.org/research/about-state-legislatures/summaries-of-term-limits-cases.aspx 
A partir de esta condición y habida cuenta que tal restricción constituye un requisito adicional para los cargos públicos, una ley ordinaria no puede incorporar condiciones materiales adicionales que afectan al desarrollo directo del derecho de participación política cuando la Norma fundamental no las establece siendo preceptiva que su introducción se realice contando con una habilitación previa constitucional.

\section{La restricción del número de mandatos afecta a las relaciones interinstitucionales y supone una triple limitación que condiciona a los sujetos intervinientes en el procedimiento ordinario de nombramiento tal y como lo configura la Norma fundamental}

La importancia de la constitucionalización del procedimiento de investidura ha sido subrayada por la doctrina ya que está en la base de las relaciones interinstitucionales en los sistemas parlamentarios ${ }^{29}$. De la regulación contenida en el artículo 99 de la Constitución se deriva el rol del Monarca en el parlamentarismo español, el papel protagonista de los partidos políticos y la centralidad del vínculo fiduciario entre el Parlamento y Gobierno.

En nuestro país, la Constitución contiene una regulación muy abierta y flexible en lo que se refiere a la formación del Gobierno en la fase de nombramiento del Presidente. El artículo 99 menciona cuáles son los órganos implicados y las actividades que desarrolla cada uno de ellos sin entrar en detalles como las condiciones de las candidaturas, el orden de la consulta regia, la categoría del representante político designado para la consulta, las consecuencias de la inactividad del Monarca, la posibilidad de renuncia del candidato propuesto, la inadecuación de la propuesta del Rey a la razón de ser del artículo 99 (la formación del Gobierno), los plazos para la realización de la propuesta regia del candidato o la convocatoria del Pleno de investidura, etc. Este carácter abierto es una opción consciente del constituyente de forma que la función de nombramiento se ha ido desarrollando conforme a una tradición política que ha dado lugar a un protocolo no escrito en el que la mayor virtualidad consiste en la amplitud con la que se configura la intervención del Monarca, la libertad con la que los partidos políticos participan en ella y la elección del Congreso. La restricción del número mandatos supondría, por tanto, una triple limitación.

En relación con el Monarca entendemos que es preceptiva la modificación del artículo 99.1 de la Constitución para introducir el requisito de acceso al cargo que afectaría a los candidatos a la Presidencia del Gobierno. Esta reforma viene avalada por el hecho de que el actual artículo 99 de la Constitución no impone ningún límite material al candidato que el Rey presenta ante el Congreso tras las preceptivas consultas. La Norma fundamental no exige ninguna condición de estatus para el propuesto: no debe ser parlamentario, ni líder de la formación respectiva, tampoco se

29 Por todos, Joan Vintró Castells, La investidura parlamentaria del Gobierno: perspectiva comparada y Constitución española, cit., pág. 15. 
exige que el partido o coalición haya constituido grupo parlamentario propio. Es más, la Constitución se limita a no establecer incompatibilidad alguna entre la candidatura o el ejercicio de la presidencia del Gobierno y la función parlamentaria ${ }^{30}$. Relacionado con lo primero, la Constitución permite que el Gobierno incluya entre sus integrantes a quienes no sean miembros electos de las Cámaras. En cuanto a lo segundo, el artículo 70.1.b) de la Constitución excluye de manera expresa a los miembros del Gobierno del listado de cargos públicos incompatibles con la función de diputado o senador.

El sistema constitucional español caracterizado por el artículo 1.3 CE como una monarquía parlamentaria se manifiesta como tal en momentos cruciales del funcionamiento del mismo como es la formación ordinaria del Gobierno. La propuesta del Rey es un acto de relación constitucional entre la Corona y el Congreso de los Diputados y puede entenderse incluso incardinada en la función arbitral y moderadora que reconoce el artículo 56.1 de la Constitución ${ }^{31}$. Jurídicamente, la selección de candidatos está escasamente formalizada y el Monarca tiene libertad de elección para proponer al candidato que desee dentro de unos márgenes que varían en función del contexto parlamentario en el que tiene lugar el nombramiento. Como advirtió García Pelayo, por un lado, el Derecho Constitucional no se agota en los preceptos normativos habida cuenta del importante papel jugado por las costumbres y convenciones en este ámbito y, por otro lado, no es posible comprender los preceptos constitucionales en su aislamiento sino en relación con las situaciones políticas ${ }^{32}$. Así, la propuesta regia parte del doble condicionamiento que supone para su ejercicio la correlación de fuerzas existente en el Congreso y la finalidad que se persigue con la propuesta pero es sabido que este margen discrecional del Monarca se amplía concediéndole cierto protagonismo cuando no existen mayorías parlamentarias claras y deba aventurarse a descubrir al candidato con mayores expectativas de respaldo parlamentario. Fuera de este espacio, la decisión del Rey de proponer a un candidato no viene restringida por ningún condicionamiento constitucional.

Por lo que se refiere a los partidos políticos, entre las principales funciones que realizan en el Estado contemporáneo, se encuentra precisamente la de efectuar una selección de las elites gobernantes ${ }^{33} \mathrm{y}$, en la actualidad, la función de selección de candidatos a la Presidencia del Gobierno ha pasado a estar monopolizada casi exclusivamente por estas organizaciones «que han hecho de ella una de sus principales

30 Antonio Bar Cendón, «Nombramiento del Presidente del Gobierno»..., pág. 279. Sobre la institución monárquica, por todos, VVAA, Monarquía y Constitución, A. Torres del Moral (dir.), COLEX, Madrid, 2001.

31 Miguel Herrero de MiÑón, «Les sources étrangères de la Constitution», Pouvoirs, núm. 8, 1987 , págs. 105 y 106.

32 Manuel García Pelayo, «Segundo círculo y decisión consensuada», Documentación Administrativa, núm. 188, 1980, págs. 23 y 24.

33 Manuel García Pelayo, Democracia y Estado de partidos, CEPC, 1983. 
misiones» ${ }^{34}$. Como ya sabemos, la dicción del artículo 99 deja claro que el protagonismo en la fase de consulta no corresponde a los grupos parlamentarios sino a los «grupos políticos» que han obtenido representación en las Cortes Generales. En la práctica, las consultas regias se evacuan con los representantes que designan los partidos políticos por lo que la nominación de un candidato ha de ser verificada únicamente por el órgano competente del partido. Así, la limitación del número mandatos afectaría gravemente a la libertad de selección del candidato de los partidos políticos a quien, recordamos, la Norma fundamental no impone ninguna condición de estatus. Sintéticamente, «el jefe del gobierno es designado para ese puesto porque es el jefe de un partido que está en situación de formar gobierno» ${ }^{35}$. La imposición de esta condición a los partidos políticos que están en condiciones de otorgar una mayoría parlamentaria a sus candidatos restringe injustificadamente la garantía institucional de los mismos asignada por la Constitución que los considera «instrumentos fundamentales de la participación política» (artículo 6 de la Constitución) y los coloca en la posición de promover la participación política individual concurriendo a su formación y manifestación (STC 10/1983, de 21 de febrero, fj 2).

Precisamente, es necesario analizar la razón de ser de esa limitación para saber si vulnera la libertad de los partidos políticos a confeccionar candidaturas porque cabe imponer obligaciones a los partidos políticos siempre que la finalidad sea constitucionalmente legítima, proporcional. Así, por ejemplo, la imposición de paridad en las listas electorales fue avalada por el Tribunal Constitucional en su sentencia 12/2008, de 29 de enero. El objetivo que persigue la limitación del número de mandatos es básicamente el de la regeneración democrática pero, como razonábamos unas líneas más arriba, se trata de una motivación insuficiente para condicionar la libertad de selección de los partidos porque «pese a la importancia que tiene la alternabilidad en el gobierno para la teoría democrática, ella por sí sola no es un principio mismo de la democracia, comparable con el principio de elección de los mandatarios y de la periodicidad de las elecciones» ${ }^{36}$. Los partidos políticos pueden tener interés en mantener como candidato al líder que ya posee experiencia y conocimientos sin los cuales pueden producirse consecuencias negativas (por ejemplo, debilidad del Ejecutivo frente al legislativo, pérdida de peso político y de liderazgo en el Gobierno, menor productividad, etc.).

En este sentido, por coherencia con la autonomía de las organizaciones políticas y el carácter voluntario de la decisión, resulta más conveniente que los límites a la dura-

${ }^{34}$ Luis AguiAr, «La estructura del proceso de formación de Gobierno. El caso español en el marco del derecho comparado», Revista del Departamento de Derecho Político, núm. 6, 1980, pág. 69.

35 Jean-Claude Colliard, Los regímenes parlamentarios contemporáneos, Blume, Barcelona, 1981, pág. 338.

36 Dieter NoHLen, «La reelección», en Tratado de Derecho Electoral comparado de América Latina, D. Nohlen, D. Zovatto, J. Orozco, J. Thompson (comps.), FCE, Instituto Interamericano de Derechos Humanos, Universidad de Heidelberg, International IDEA, Tribunal Electoral del Poder Judicial de la

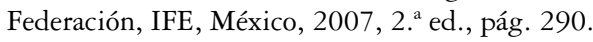


ción en los cargos se ubique en las normas internas de los partidos como ocurre actualmente en los Estatutos de Izquierda Unida ${ }^{37}$, Ciudadanos ${ }^{38}$, Esquerra Republicana ${ }^{39}$, Partido Nacionalista Vasco ${ }^{40}$ o, con matices, Partido Socialista Obrero Español ${ }^{41}$.

En cuanto al Congreso de los Diputados, la intervención parlamentaria es el momento más relevante de todo el proceso de formación del Gobierno, el elemento constitutivo de la formación de la voluntad estatal en este punto. Con la inclusión de una limitación a la reelección presidencial limita materialmente la capacidad de designación de la Cámara baja puesto que, en sentido estricto, no es una elección entre varios candidatos sino que se debe otorgar o no la confianza en aquel que se presenta en cada ocasión $^{42}$. Como hemos visto, el derecho a presentar el candidato es un derecho del partido y la decisión de elegir o no a un candidato corresponde al pueblo. Afecta, pues, al derecho de los electores de elegir a sus gobernantes y al derecho de los representantes a elegir al candidato que prefieran.

La limitación del número de mandatos que impide a ciertas personas que se presenten o participen en procesos electivos se configura, como vimos, como una institución de garantía cuyo significado último es proteger el derecho a la libre formación de la voluntad electoral. Es al constituyente a quien corresponde asumir la responsabilidad de establecer el principio de la inexistencia del derecho de sufragio pasivo y las condiciones materiales o causas que restringen su ejercicio. Porque en última instancia lo que se está afectando es el derecho de los representantes de la soberanía popular a entablar una relación fiduciaria con un candidato que cuenta con el apoyo de la mayoría de la Cámara reduciendo también el margen de elección del cuerpo electoral.

37 Artículo 16 de los Estatutos de IU: «Los cargos públicos electos de IU no podrán permanecer en el mismo cargo, de manera continuada, más de dos legislaturas naturales, u ocho años, si hay elecciones anticipadas».

38 Artículo 5.6 de los Estatutos de Ciudadanos: «Ninguna persona podrá desempeñar un cargo público con responsabilidad de gobierno en representación del Partido más de dos legislaturas completas, o bien cuatro legislaturas si lo desempeñase en instituciones de distinto nivel administrativo».

39 Artículo 121 de los Estatutos de ER: «La duración máxima de forma interrumpida en un mismo cargo público institucional de carácter ejecutivo y supralocal, en representación de Esquerra Republicana, no será superior a 12 años, si bien siempre se puede acabar el mandato».

40 Artículo 95.1 de los Estatutos de EAJ-PNV: «Los cargos ejecutivos de elección popular o de designación fuera de EAJ-PNV son incompatibles con los cargos internos, tanto ejecutivos como legislativos del mismo ámbito territorial, salvo en Organizaciones Municipales de menos de 100 afiliados y afiliadas, en las que la Asamblea Municipal podrá levantar la incompatibilidad entre cargo interno municipal y cargo público del mismo nivel».

41 Disposición adicional quinta de los Estatutos del PSOE: «Ningún cargo orgánico ejecutivo podrá ser ocupado por la misma persona durante más de tres mandatos consecutivos, salvo en el caso de la secretaría general, cuando su titular ejerza la presidencia del gobierno de España o la presidencia del gobierno de la respectiva comunidad autónoma, o la Alcaldía de Ayuntamiento del mismo ámbito».

42 Antonio Torres del Moral, Principios de Derecho Constitucional Español, Tomo II, Servicio de Publicaciones Facultad de Derecho, Universidad Complutenses Madrid, Madrid, 2004, págs. 173 y 174. Del mismo autor encontramos una esclarecedora aproximación a los conceptos de representación, participación y elección en Estado de Derecho y democracia de partidos, cit., págs. 353 a 355. 


\section{CONCLUSIONES}

Parafraseando las reflexiones contenidas en el mencionado informe de la Comisión de Venecia, «los efectos de los límites en las instituciones democráticas de un país dependen en gran medida de su dimensión constitucional, su realización práctica y sobre todo el poder del modelo de organización en el país, es decir, el tipo de régimen de naturaleza parlamentaria, carácter presidencial o mixta» ${ }^{43}$, esto es, el contexto histórico, social y político en el cual se aplican estas normas de limitación del número de mandatos presidenciales. Esto significa que, en el momento de introducir un nuevo requisito para acceder al cargo de Presidente del Gobierno, nos debemos cuestionar acerca del para qué y el cómo.

En relación con el primer interrogante son claros los objetivos que persigue la limitación del número de mandatos de un cargo público. Se trata, principalmente, de una medida de saneamiento democrático, de regeneración de elites políticas que apela a la renovación en el interior de los partidos políticos y a la entrada de nuevas generaciones e ideas en los órganos de extracción popular y sus titulares ${ }^{44}$.

Sin embargo, en las páginas anteriores hemos dejado constancia de la existencia de esa restricción en las normas internas que ya están rigiendo en casi la totalidad de los partidos políticos del espectro parlamentario tanto nacional como regional. Únicamente los dos partidos «tradicionales» quedan fuera del listado — los Estatutos del PP no mencionan ningún límite a la duración de los mandatos de sus cargos electivos y los Estatutos del PSOE excepcionan, entre otros, el puesto de Presidente del Gobierno de la regla de incompatibilidad entre cargos orgánicos y electivos - lo que resulta revelador ya que a ellos parece dirigida principalmente la propuesta y está relacionado con un contexto político en el que eran las formaciones con posibilidades de alcanzar la titularidad del Ejecutivo. Pero este panorama ha cambiado radicalmente y entendemos que la influencia de las reglas internas del resto de organizaciones se apreciará en breve como consecuencia natural del nuevo diseño parlamentario.

La limitación del número de mandatos del presidente del Gobierno constituye un requisito de acceso al cargo cuyos efectos son, en general, muy estrictos porque impide la prolongación personal de un mandato lo que suscita dudas por su incidencia tanto en el derecho electoral pasivo como en el derecho a elegir a los titulares de los órganos públicos en una forma de gobierno parlamentaria y basada en la democracia representativa. Además, es necesario tomar en consideración la eficacia de la medida en un contexto de democracia de partidos en la que los votantes eligen entre formaciones políticas y no entre individuos.

43 Comisión Europea para la democracia a través del derecho del Consejo de Europa, Rapport sur la démocratie, la limitation des mandats et l'incompatibilité de fonctions politiques, cit., pág. 5.

44 Antonio Estella, «Por la limitación de mandatos en la política», El País, 15 de junio de 2013. 
Asimismo, la importación de este instrumento desde sistemas presidenciales fuertes y centralizados puede no encajar bien en un sistema de gobierno parlamentario. En los sistemas parlamentarios los problemas de no reelección del Jefe del Estado se plantean en las Repúblicas parlamentarias, nunca en el contexto de monarquía constitucional por el carácter hereditario y vitalicio de la institución. Y, por lo que se refiere a la figura del Jefe de Gobierno, el traslado de esta condición de acceso no encaja bien con la relación fiduciaria que mantiene el Gobierno y su titular con la cámara parlamentaria que decide sobre la duración del mandato (no renovándose tras nuevas elecciones o acortándolo por efecto de instrumentos como la moción de censura).

Pero también es importante tomar en consideración las circunstancias concretas que legitiman esta previsión en aquellos sistemas presidenciales como son la permanencia en el cargo durante periodos muy extensos y fijos (supuesto de Estados Unidos) o la exclusión de la alternancia por fraude (supuesto de los países latinoamericanos) y decidir si la limitación del número de mandatos puede gozar del mismo grado de legitimación en un contexto diferente ${ }^{45}$. Esto es, en un ámbito democrático donde la alternancia en el gobierno está garantizada por elecciones periódicas confiadas al juego libre de las fuerzas políticas. Además deben tenerse en cuenta valores y conceptos como el de responsabilidad ya que la prohibición de reelección limita la capacidad de los votantes de someter a control el ejercicio del poder del mandatario y esto podría introducir incentivos para no escuchar a la ciudadanía.

Por otra parte y en relación con el modo de articular la propuesta de restringir la reelección, hemos defendido la necesidad de incluirla en el Texto constitucional mediante la reforma del artículo 99 porque supone una triple limitación que afecta directamente y sin fundamento constitucional a las funciones del Rey, de los grupos políticos proponentes y del Congreso. El precepto constitucional que regula el procedimiento ordinario de investidura del Gobierno no impone ninguna condición material por lo que es preceptiva la previa habilitación constitucional para reproducir esa condición en una norma de rango legal. Por tanto, la remisión legal que realiza el artículo 98.4 de la Constitución para que se regule el «estatuto e incompatibilidades de los miembros del Gobierno» no ampara la hipotética modificación de la Ley del Gobierno para establecer la cláusula de no reelección.

El inconveniente de nuestra apuesta es notable puesto que acudir a la vía de la reforma constitucional en España es una tarea ardua aunque, en este caso, se trataría de la reforma ordinaria del artículo 167 de la Constitución, que requiere una mayoría de tres quintos de cada Cámara, puesto que el procedimiento ordinario de investidura del Gobierno no se halla entre las materias protegidas por el mecanismo de reforma agravado del artículo 168 de la Constitución.

45 Dieter NoHLEN, «La reelección», en Tratado de Derecho Electoral comparado de América Latina, cit., pág. 290. 
Corresponde, finalmente, a los representantes de la soberanía popular decidir sobre la oportunidad de la medida, su impacto en el funcionamiento real de la democracia y su eficacia concreta para actuar sobre la recurrente demanda de regeneración democrática.

Title:

The term limits of the Presidential office

\section{Summary:}

I. Introduction. II. The proposal of limiting the number of terms of office of the president of the Government and the current prescriptions of limits of term of office of the presidents of the autonomous regions. III. The need for a constitutional reform to set the limitation of the number of terms of office of the president of the Government. Arguments. 1. The limitation of the number of terms of office of the President is inconsistent with the parliamentary system. 2. The eligibility of a person is part of the representative democratic tradition. 3. The limitation of the number of terms of office ignores the logic of the State of the parties. 4 . The restriction of terms of office affects the relations among institutions and represents a triple constraint that determines the subjects involved in the procedure of appointment of the President of the Government. 5. The limit of the terms of office is a vetoed subject for the Government Act as it exceeds the content authorized by the Constitution. IV. Conclusions.

\section{Resumen:}

En España, en los últimos tiempos, se ha hablado y discutido con frecuencia sobre la posibilidad de limitar el número de mandatos de los Presidentes del Gobierno. La propuesta más reciente ha sido abordada por el grupo parlamentario Ciudadanos con la presentación de una Proposición de modificación de la Ley del Gobierno de 1997. El principal motivo que se esgrime para incorporar esta novedad es el de contribuir a la regeneración democrática y evitar episodios de perpetuación en el cargo público. Pero la propuesta ha desencadenado un debate jurídico muy intenso sobre la norma jurídica que debe contener el mandato. De modo que, frente a quienes defienden la legitimidad de la opción legal, existen sectores políticos y doctrinales que abogan por la necesidad de acometer una reforma constitucional sobre la base de las dificultades de encaje de tal medida en el sistema parlamentario español y la incidencia que tiene en el procedi- 
miento ordinario de nombramiento del Presidente del Gobierno en los términos que establece el artículo 99 de la Constitución española.

\begin{abstract}
:
In Spain, the idea of limiting the number of terms of office of the President of the Government has been around in recent times. The parliamentary group Ciudadanos has addressed this issue with a Proposal of amendment in the Government Act of 1997. The requirement is justified on the contribution to the democratic regeneration and the prevention of perpetuation in a public office. But the proposal has triggered an intensive debate and, against those who defend the legitimacy of the legal amendment, some sectors support the need for a constitutional reform on the basis of the inconsistencies with the Spanish parliamentary system and the impact on the ordinary procedure of appointment of the President of the Government, under the terms provided by article 99 of the Spanish Constitution.
\end{abstract}

\title{
Palabras clave:
}

Presidente del Gobierno, mandato, sistema parlamentario, democracia, derecho de sufragio.

\section{Key words:}

President of the Government, terms of office, parliamentary system, democracy, voting rights (right to vote and be elected). 